Fifth International Conference on Sustainable Construction Materials and

Technologies. http://www.claisse.info/Proceedings.htm

\title{
FEASIBILITY STUDY ON PRODUCTION OF FIBRE CEMENT BOARD USING MORTAR REINFORCED BY FIBREGLASS NET AND POLYPROPYLENE FIBRES
}

\author{
Ali Younesian ${ }^{1}$, Mahmoud Nili ${ }^{2}$, Alireza Azarioon ${ }^{3}$ \\ ${ }^{1}$ Civil Engineering Department, Bu-Ali Sina University, Hamedan, IRI, aliyounesian76@ gmail.com \\ ${ }^{2}$ Associate Professor, Civil Eng. Dept., Bu-Ali Sina University, Hamedan, IRI, nili36@yahoo.co.uk \\ ${ }_{3}^{3}$ Assistant Professor, Civil Eng. Dept., Malayer University, Malayer, IRI, azarioon@ gmail.com
}

\begin{abstract}
The need for sustainable, environmental-friendly, energy-efficient, low-cost construction materials could justify the interest in fibre cement board production with lower cement content. This research attempts to reduce cement content by utilization cement in combination with fine sand in a specific size, based on mortar mixture design. In this research, fibreglass net and polypropylene fibre which are generally used in the fabric industry were used to improve flexural behaviour of fibre cement board that can be used as an internal/external wall as well as materials for roofing.

Mechanical/physical characteristics of the specimens include flexural strength, density and water absorption were tested and analyzed according to relevant standards.

The results showed that the specimens made of mortar mixture reinforced by fibreglass net and polypropylene fibre could meet the standard requirements, and results in considerable reduction in cement content about $30 \%$ in volume.
\end{abstract}

Keywords: Fibre cement board, Sustainable material, Polymeric fibres, Mortar, Fibreglass net

\section{INTRODUCTION}

Nowadays, fibre cement boards (FCBs) have been used as an internal/external walls as well as material for roofing and cladding. It should be noted that this construction material is not widely accessible in many developing/ least developed countries. This can illustrate the justification of researching on FCB to remove traditional construction systems.

The reduction of cement content is one of the persistent global sustainability concerns of the 21 st century. Of all the ingredients in FCB, cement has the largest footprints when it comes to both carbon dioxide release and energy consumption [1]. Although, numerous reasons exist that high cement content in construction materials is a paramount factor in lack of sustainability and environmental friendliness, high level of cement is still used in the production of FCB in many of developed countries.

The most research studies in recent years have focused on the type of fibre used as a replacement of asbestos fibres because of recognition of asbestos hazards on human health and fewer of them have tried to reduce cement content using some materials such as limestone powder and silica fume in very low replacement percentages [2-4]. 
This study attempts to reduce cement content by utilization of cement in combination with fine sand, in a specific size, based on mortar mixture design [5]. Fibreglass net and polypropylene fibres were used to reinforce mixture and improve the flexural behaviour of FCB.

In order to emphasize how the application of FCB as a lightweight, sustainable and environmental-friendly new construction material can help users of a building to survive during an intensive earthquake with longtime ground shaking performance of masonry walls in comparison with FCB walls in recent 2017 Sarpol-e Zahab earthquake is investigated. According to the report of International Institute of Earthquake Engineering and Seismology [6], the magnitude of this earthquake was 7.3 in the focal depth of $11 \mathrm{~km}$ and damaged too many people and buildings. Fig. 1 is just a glimpse of this natural hazardous event. As seen in Fig. 1, while the masonry wall was collapsed, the FCB wall resisted during the earthquake. It seems that even if the building can resist structurally, the users may get hurt by some destroyed nonstructural elements in building such as a massive masonry external wall. This consideration clarifies the importance of using lightweight, sustainable and environmental-friendly construction materials with high-quality such FCB. This research can compensate the lack of this manner in countries like Iran by substitution of FCB instead of traditional masonry wall systems which are still used in many regions in Iran to help the construction industry to build safer buildings.

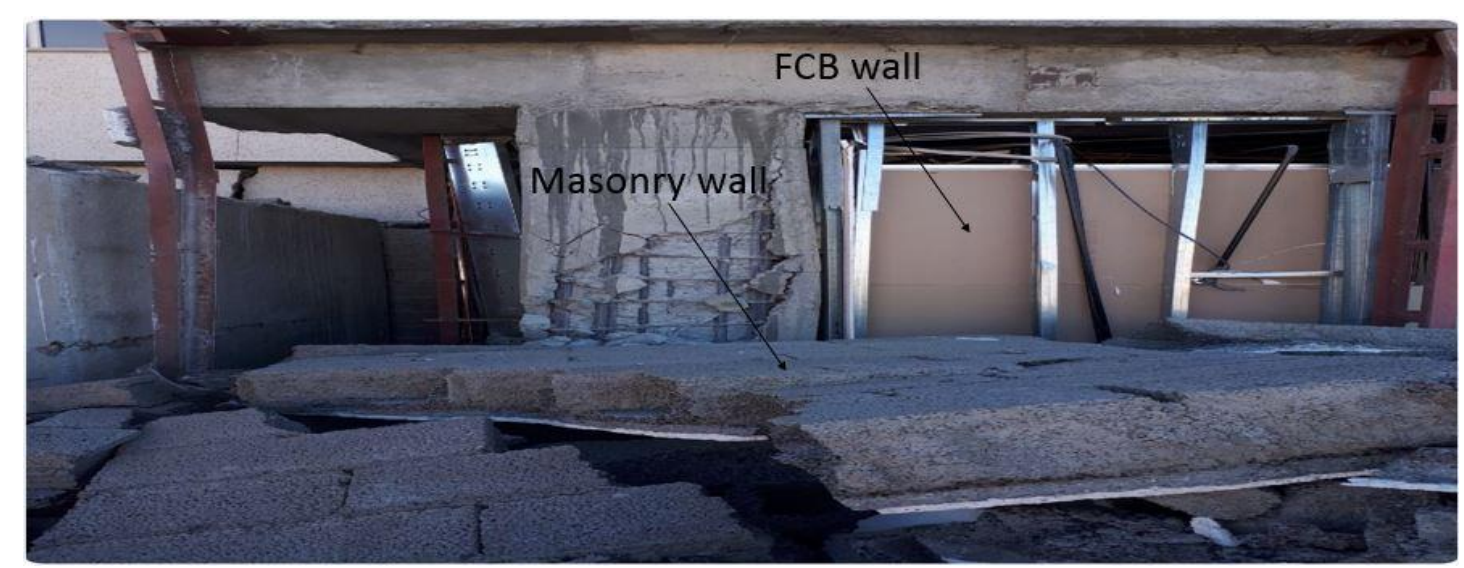

Fig. 1 Performance of masonry and FCB walls in recent Sarpol-e Zahab earthquake

\section{MATERIALS AND EXPERIMENTAL PROCEDURES}

The following materials were used in the mix to produce specimens in the Lab:

- Ordinary Portland Cement

- Fine sand (passed from \#8 and is remained on \#200)

- $5 \mathrm{~mm} \times 5 \mathrm{~mm}$ fibreglass net

- $15 \mathrm{~mm}$ polypropylene fibre

In this research, the first two groups of low and high cement mortar mixtures were produced and then were reinforced by fibreglass net. Preliminary low-cement mortar mixes were designed with the utilization of 405 and $1085 \frac{\mathrm{kg}}{\mathrm{m}^{3}}$ cement and fine sand respectively, to gain an impressive reduction in cement content. The main problem in low-cement mortar panel was that it could not satisfy the relevant requirements in flexural strength standard. So material preparation has been prepared on high-cement mortar to investigate the effect of fibres. Therefore, a modified $945 \frac{\mathrm{kg}}{\mathrm{m}^{3}}$ cement and 
$465 \frac{\mathrm{kg}}{\mathrm{m}^{3}}$ fine sand, were used for producing of high-cement mortar. The effect of $0.75 \%$ and $1.5 \%$ volume fraction of polypropylene fibres with and without fibreglass net was investigated in high-cement mortar. The amount of water $\left(338 \frac{\mathrm{kg}}{\mathrm{m}^{3}}\right)$ was constant. The size of sand was chosen according to the size of fibreglass net. The proportions of materials are given in Table 1 for a $160 \times 160 \times 15 \mathrm{~mm}^{3}$ vacuum mould .

In the mix codes, the abbreviations were defined as follows:

'H'; High-cement, 'L'; Low-cement, 'PP'; Polypropylene fibre (followed by its percentage) and 'F'; fibreglass net. For example, PP0.75-F denotes that there is a $0.75 \%$ polypropylene fibre incorporation with fibreglass net.

Table 1. Mix Proportions of FCBs

\begin{tabular}{llllll}
\hline $\begin{array}{l}\text { Mix } \\
\text { Code }\end{array}$ & $\begin{array}{l}\text { Cement } \\
\text { (gr) }\end{array}$ & $\begin{array}{l}\text { Sand } \\
(\mathbf{g r})\end{array}$ & $\begin{array}{l}\text { PP } \\
(\mathbf{g r})\end{array}$ & $\begin{array}{c}\text { Fibreglass } \\
\text { net }\end{array}$ & $\begin{array}{l}\text { Water } \\
\text { (gr) }\end{array}$ \\
\hline L & 150 & 420 & 0 & - & 130 \\
\hline H & 360 & 180 & 0 & - & 130 \\
\hline L-F & 150 & 420 & 0 & F & 130 \\
\hline H-F & 360 & 180 & 0 & F & 130 \\
\hline H-PP0.75 & 360 & 180 & 2.7 & - & 130 \\
\hline H-PP1.5 & 360 & 180 & 5.4 & - & 130 \\
H-PP0.75-F & 360 & 180 & 2.7 & F & 130 \\
\hline H-PP1.5-F & 360 & 180 & 5.4 & F & 130 \\
\hline
\end{tabular}

\section{MATERIAL PREPARATION AND TESTS}

A $160 \times 160 \times 15 \mathrm{~mm}^{3}$ vacuum mould with a removable cover was used to make each panel without any pressure. The procedure used for making FCBs is as follows: the bottom fibreglass net was placed in the mould, the mortar was poured in; then the top fibreglass net was placed and the mould was closed. Adhesion between the fibreglass net and mortar was not investigated specifically in this research, but based on experimental evidence, it develops satisfactorily with cement hydration process, without any special means. The cover was removed and panel was demoulded 2 days later with no change in $\mathrm{w} / \mathrm{c}$ ratio of specimen. The procedure of specimen's production is shown in Fig. 2 in the order of steps.
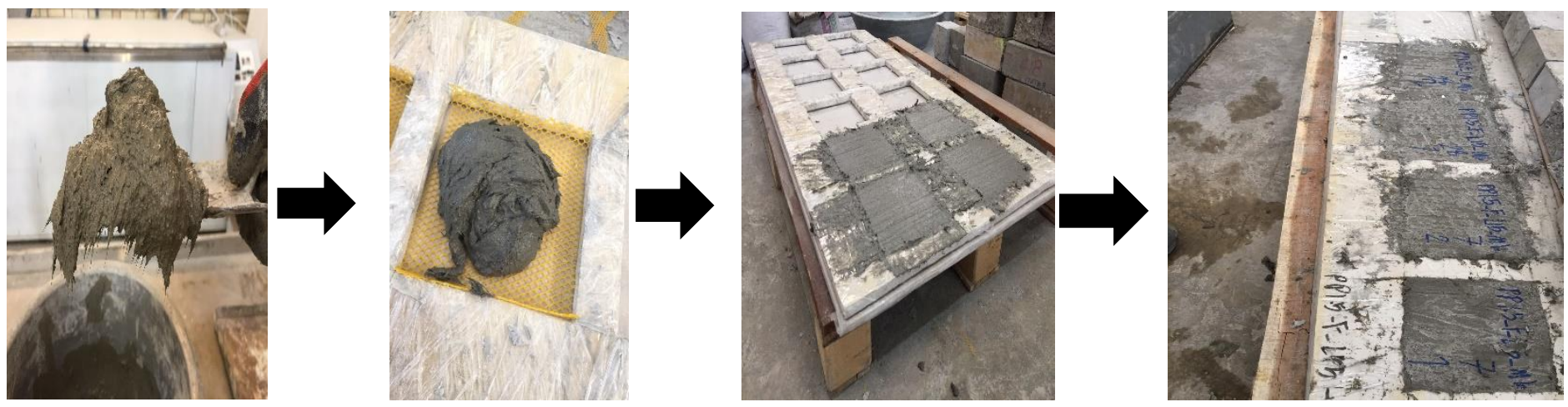

Fig. 2 Procedure of specimen's production

The solid panel was then stored in a climate chamber at $20{ }^{\circ} \mathrm{C}$ with $95 \%$ relative 
humidity for 7-28 days before mechanical tests. Four specimens were prepared from each mix. Two of them were tested at 7-day after curing and the rest at the age of 28day. In Figs. 3 and 4, the distribution of polypropylene fibres and how fibreglass net placed in specimens in the place of crack after flexural strength test are shown, respectively.

Determination of mechanical properties of FCB was done followed by the BS EN 12467:2012 standard [7]. It allows determining of the modulus of rupture that is the main bending property of FCB. Other tests contain density and water absorption have been performed accordingly. The span for flexural strength was adjusted at $80 \mathrm{~mm}$ with a span to width ratio of 1:2.

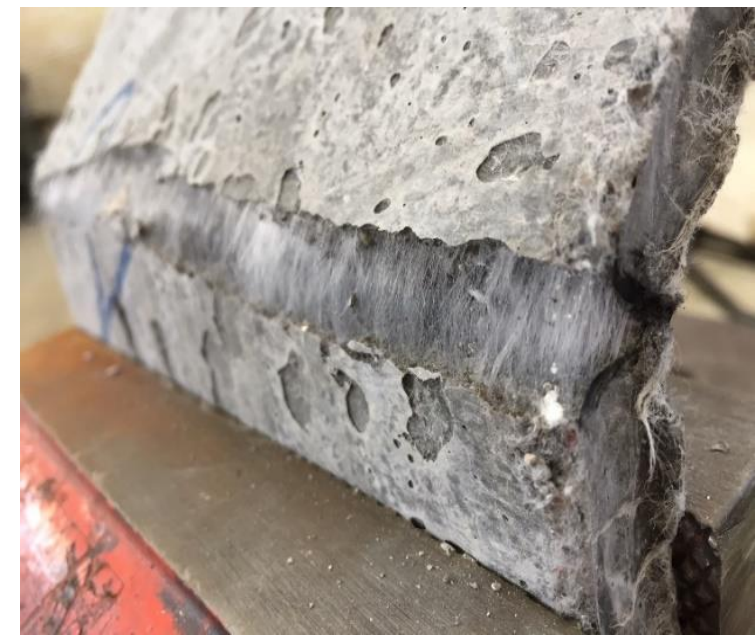

Fig. 3 Distribution of polypropylene fibres specimens

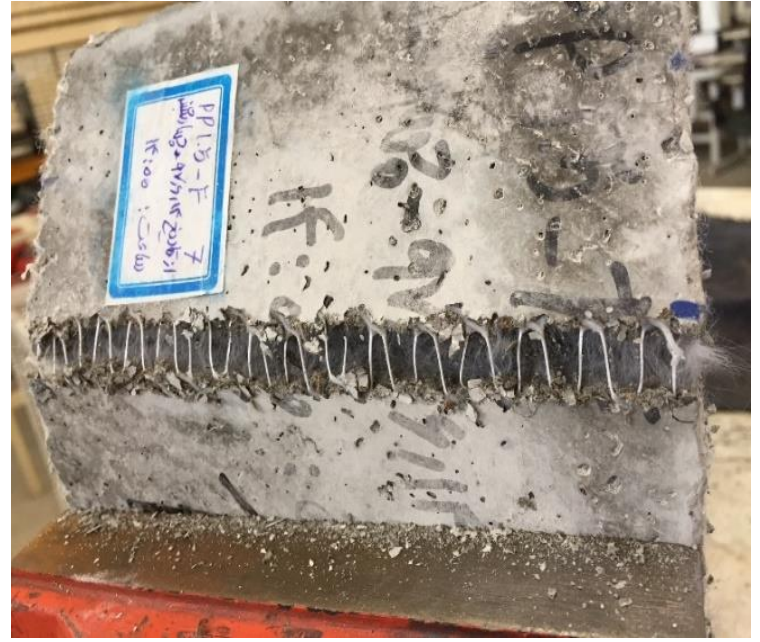

Fig. 4 How fibreglass net placed in

\section{RESULTS AND DISCUSSION}

Fig.5 shows the density of mix codes at 28-day age. The average flexural strength for all specimens aged 7-day and 28-day and water absorption content in each group is shown in Fig. 6 and Fig. 7 respectively.

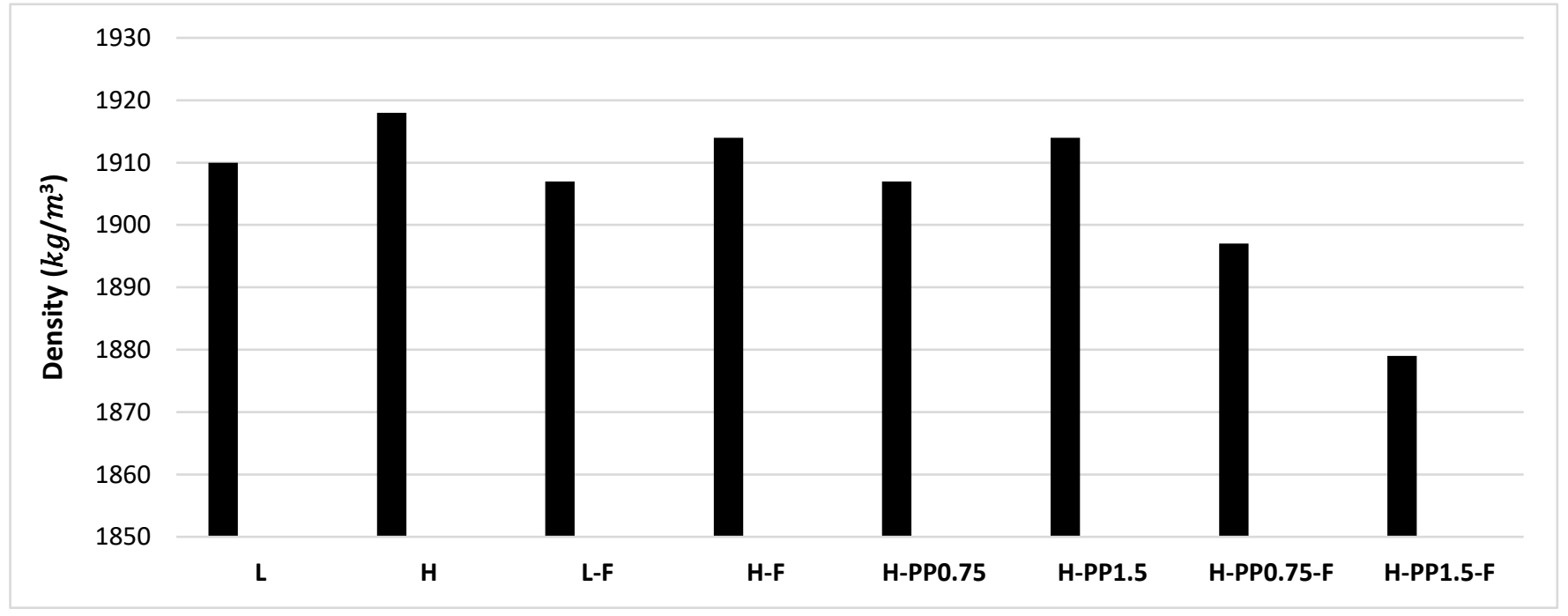

Fig. 5 Density of mixes 


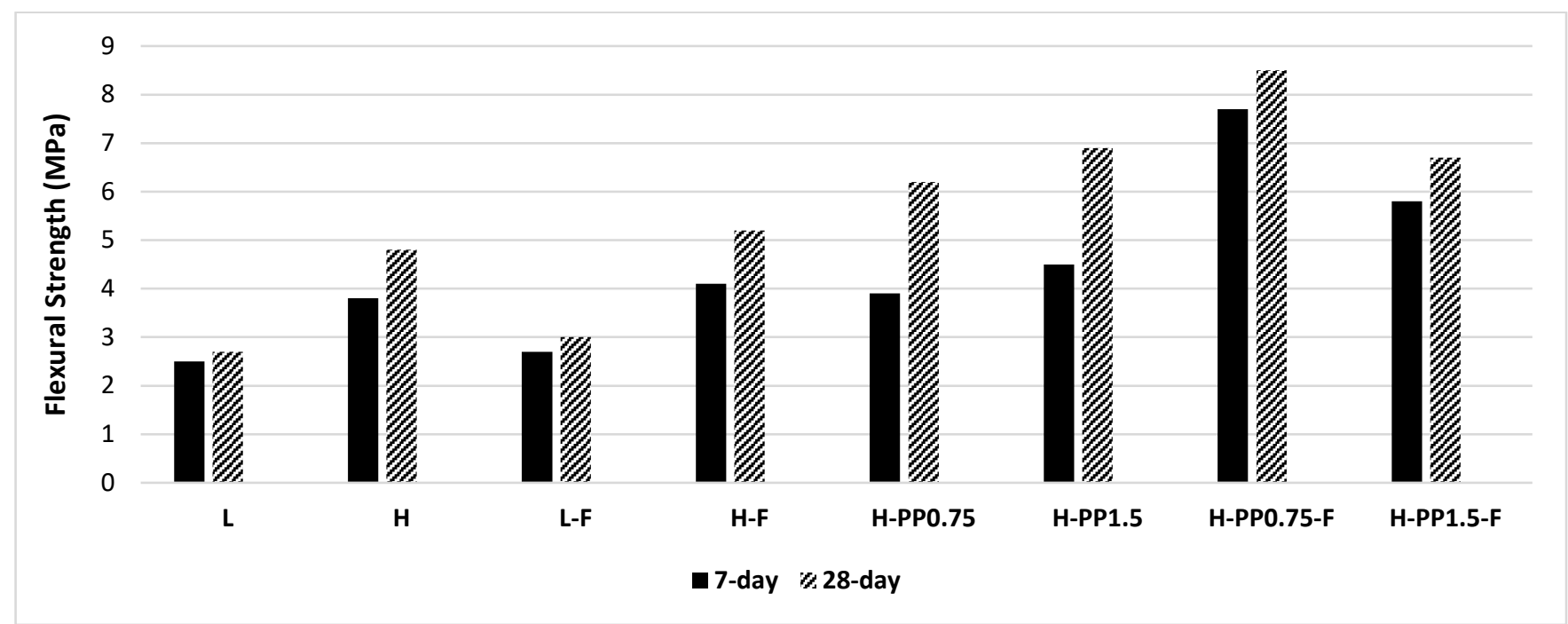

Fig. 6 Flexural strength of the mix codes

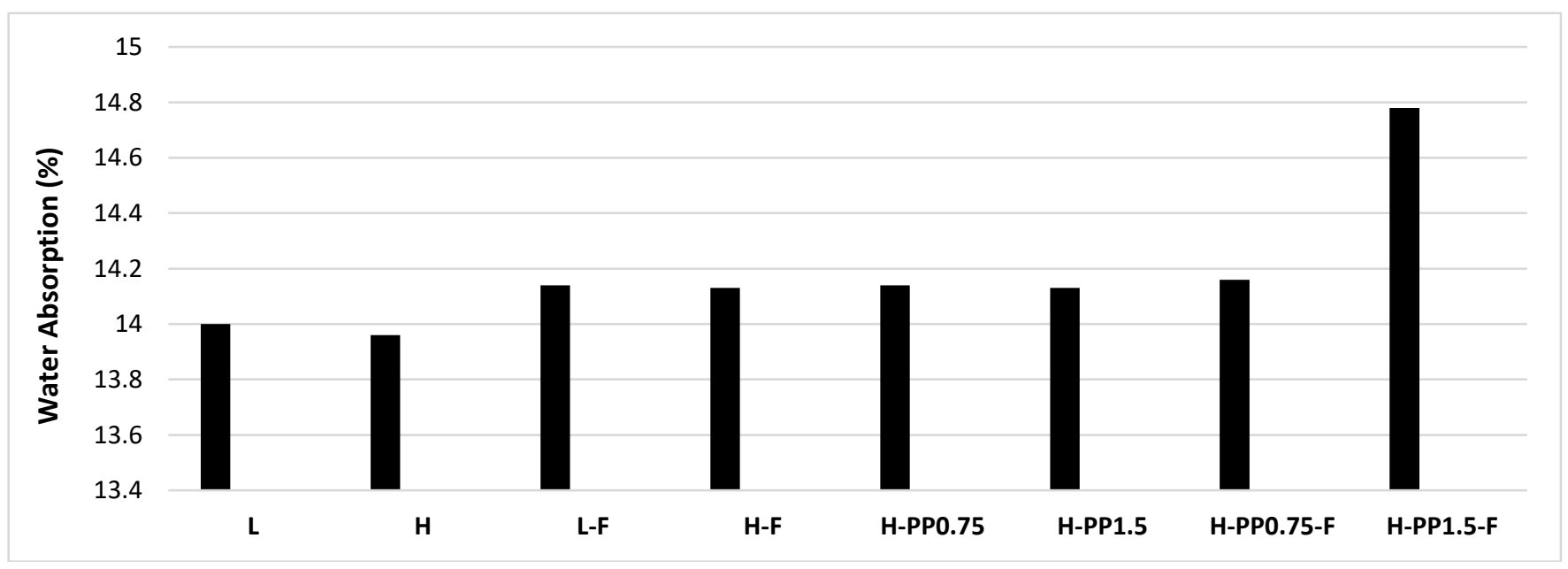

Fig. 7 Water absorption of mixes

Fig. 5 shows the density of mixes, ranged from 1879 to $1918 \frac{\mathrm{kg}}{\mathrm{m}^{3}}$ which could meet the relevant standard requirements. Water absorption contents are shown in Fig. 7 By comparison of Fig. 5 and 7 it can be concluded that highest density and lowest water absorption coincides each other

As seen in Fig. 6:

- $\quad$ Flexural strength of low-in-cement mortar mixture is too low, and fibreglass net can't compensate its weakness.

- $\quad$ By increasing the amount of PP fibres from $0.75 \%$ to $1.5 \%$, flexural strength does not increase considerably.

- Interaction of PP fibres and fibreglass net is optimum at $0.75 \%$ volume fraction of PP.

- Applying PP fibres singly cause more improvement in flexural strength of mix rather than fibreglass net.

- The maximum flexural strength within all groups (8.5MPa) belongs H-PP0.75F-28.

The flexural behaviour of all specimens at the age of 28 days is shown in Figs. 8 to 10 . 


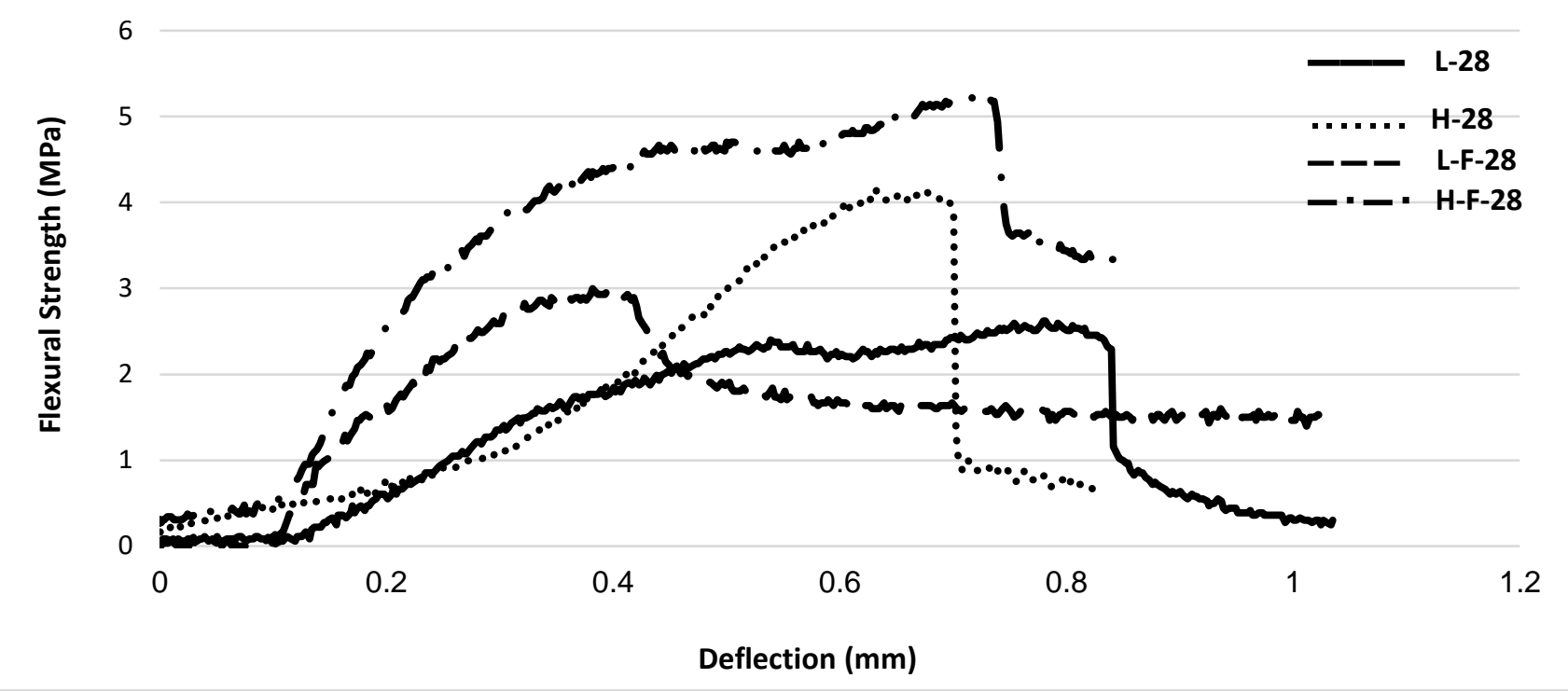

Fig. 8 Comparison of low and high-cement mixtures

Fig. 8 presents a comparison between low and high-cement mixes. Also, the effect of using fibreglass net singly is shown. Fibreglass net can increase the modulus of rupture in low-cement mortar approximately $12 \%$, and this value reaches to $20 \%$ in a high-cement mortar. This enhancement is more considerable in a high-cement mortar. As outlined in Fig. 8, the performance of R specimens is better than the L. Therefore, the $\mathrm{R}$ mix was chosen to be investigated by inserting PP fibres.

As illustrated in Fig. 9, the positive effect of enhancing PP volume fraction from $0.75 \%$ to $1.5 \%$, is not enough to justify the using of this content economically. As observed in Figs. 9 and 10, fracture toughness which relates to the area under the curve for the specimens reinforced by PP are approximately equal to other specimens reinforced by PP and fibreglass net. This means that the utilization of PP incorporation with fibreglass net has more effective to increase flexural strength rather than the ductility of specimens.

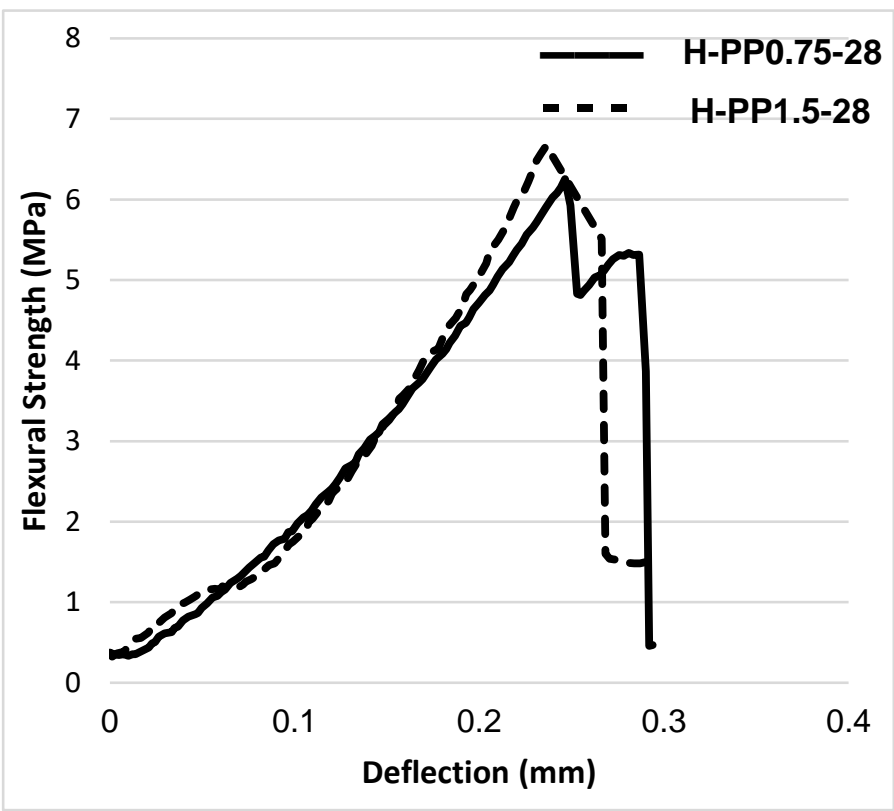

Fig. 9 Flexural performance of 28-day aged mixtures reinforced by PP fibres net

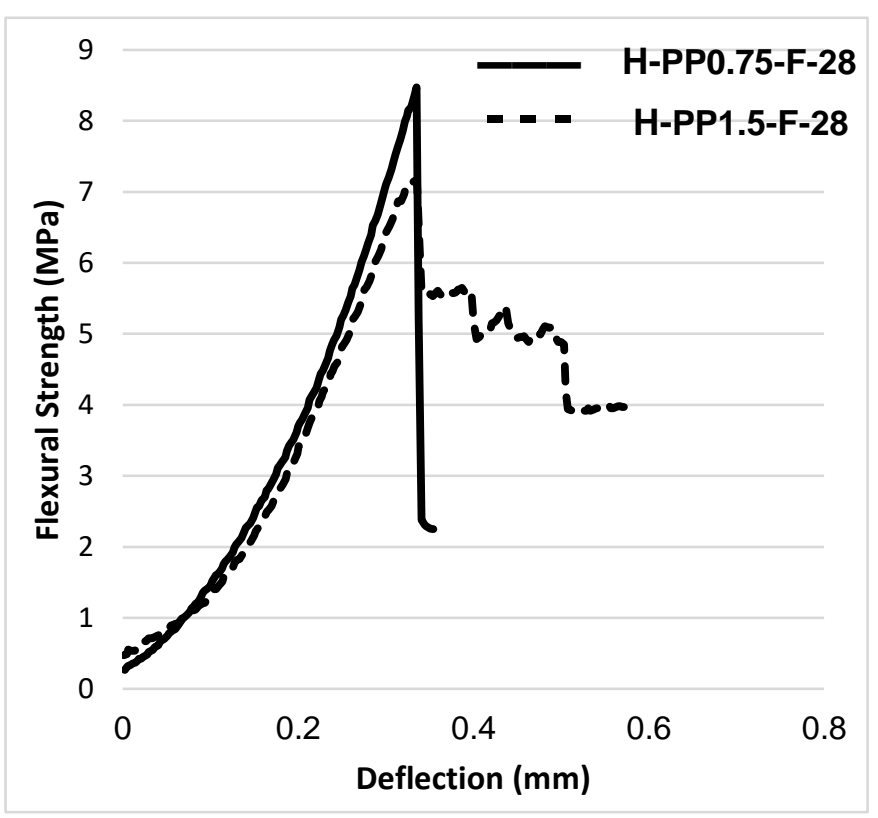

Fig. 10 Flexural strength of mixtures reinforced by PP and fibreglass 


\section{CONCLUSION}

In this experimental research, the feasibility of production of FCB based on mortar mixture design was investigated for a reduction in cement content. Polypropylene fibres and fibreglass net were used to reinforce FCB. The results show a $30 \%$ reduction in cement content by using high-cement mortar mix. PP fibres and fibreglass net cause $44 \%$ and $8 \%$ improvement in flexural strength of FCB individually and $77 \%$ in combination. The maximum flexural strength was obtained by using $0.75 \% \mathrm{PP}$ in corporation with fibreglass net.

\section{REFERENCES}

[1] Bentz, Dale P., et al. (2017). "Limestone and silica powder replacements for cement: Early-age performance." Cement and Concrete Composites 78: 43-56.

[2] Ikai, S., et al. (2010). "Asbestos-free technology with new high toughness polypropylene (PP) fibers in air-cured Hatschek process." Construction and building materials 24.2: 171-180.

[3] Khorami, M.,Ganjian, E. and Srivastav, A. (2016). "Feasibility study on production of fiber cement board using waste kraft pulp in corporation with polypropylene and acrylic fibers." Materials Today: Proceedings 3.2: 376-380.

[4] Khorami, M. and Ganjian, E. (2013) "The effect of limestone powder, silica fume and fibre content on flexural behaviour of cement composite reinforced by waste Kraft pulp." Construction and Building Materials 46: 142-149.

[5] Newman, J., and Choo, B. S. (Eds.). (2003) Advanced concrete technology set. Elsevier.

[6] Zare, Mehdi, et al. (2017). "Preliminary report of Mw7.3 Sarpol-e Zahab, Iran earthquake on November 12, 2017." Tehran, Iran: International Institute of Earthquake Engineering and Seismology (IIEES).

[7] EN, BS. 12467 (2012). Fiber-cement flat sheets-product specification and test methods. British Standards/European Norm 12467. 
